\title{
Analysis of Enterprise Environment Cost Control under Haze Background
}

\author{
Xiuyan Xu \\ Xijing University, Shaanxi, Xi'an, 710123, China
}

Keywords: Haze, Enterprise, Environment cost control.

\begin{abstract}
Nowadays, environmental issue increasingly receives intensive attention of all sectors of society. In particular, the appearance of haze has greatly threatened normal work and living order of people in recent years. However, the researches on enterprise cost control focus on economic field for a long time, and few researches pay attention to the study on enterprise environment cost control topic. Thus, it is required to enhance analysis of enterprise environment cost control under haze background. This paper summarizes enterprise environment cost control, expounds the urgency of implementing enterprise environment cost control under haze background, analyzes the problems in enterprise environment cost control and discusses the strategy of enterprise environment cost control under haze background.
\end{abstract}

\section{Introduction}

Since 2013, dense fog appears frequently in the middle part, east and north of China. This not just seriously affects air and land traffic, but also results in great troubles to the life of local people. The person in charge of national environmental protection department admits that, since China carried out haze monitoring, the accumulative days of haze weather has exceeded 100 in Beijing-Tianjin-Hebei region, Pearl River Delta region and Yangtze River Delta region in consecutive years. Thus, we realize the serious damage of haze and the urgent need of environmental governance more clearly. In the research on enterprise ethics, an idea generally accepted by people is that enterprises should take the production mode beneficial to keep local ecological environment in their production operation process. In this way, they can expand consumers, offer green, environmentally-friendly and pollution-free products and achieve optimization of economic benefit, social benefit and environmental benefit. The enterprise is the subject of economic activity and also the consumption object of natural resources. Meanwhile, it is one of promoters of haze. In order to practically change the situation where enterprise environment tends to worsen and let their behaviors more comply with enterprise ethics, enterprises must change traditional enterprise cost control mode, enhance environment cost control and create a new way for sustainable development.

\section{Overview of enterprise environment cost control}

Enterprise environment cost control refers to control and analysis of many life cycle elements in the formation period of enterprise environment cost (including product $R \& D$ and design, raw material purchase and processing, product marketing and use, and waste recycling etc.) with corresponding methods and means. In this way, enterprises' economic benefit and environmental benefit can be uniform. Under haze background, enterprise environment cost control requires to pursue synchronous development of enterprise and society by taking reduction of waste emission amount as the operation standard. In each link of product life cycle, enterprises must consider environment cost control problem, control and reduce the waste of resources maximally and utilize recyclable environmentally-friendly package and the most environmentally-friendly technology to produce ecological products. 


\section{Urgency of implementing enterprise environment cost control under haze background}

Firstly, it is the need of promoting sustainable development. Under haze background, all sectors of society pay close attention to enterprises' operation behavior in order to achieve low-carbon development and sustainable development. Enterprises attach great importance to achieve pre-control of environment cost. For the fundamental value, this is to achieve development plan of the enterprises. Meanwhile, enterprises must implement more effective environment cost control and form more profit space in order to reduce the possible loss caused by environment.

Secondly, it is the need of promoting external competition. The probability that enterprise encounter environmental problem in the development process becomes higher and higher. Thus, various countries in the world introduce very strict policy to control the damage which may be caused by environment. Additionally, to improve brand influence and competitive strength, enterprises must change traditional production operation form, alter the mode of environment cost control and apply better environment cost control means to improve enterprise competition ability.

Thirdly, it is the need of promoting enterprise management level. Environment cost control as a comprehensive management mode mainly requires enterprises to enhance environment cost governance and control so as to facilitate improvement of enterprise ability, achieve win-win of economic benefit and environmental benefit and then offer greater help for transformation and upgrade of Chinese industry. On this basis, enterprise management personnel should formulate effective operation steps, make contributions to China's economic development and open a new development channel for global environmental governance.

\section{Problems in enterprise environment cost control}

Firstly, the concept of enterprise environment cost control falls behind. Because China has been in the extensive production state, environmental risk responsibility of a large number of enterprises is very poor. If financial workers of enterprises are required to provide the information about environment cost, it is very difficult. Large quantities of enterprises fail to feel the influence and pressure on them caused by non-release of their environment information. Thus, overall enterprise environment cost control idea of enterprises falls behind, and their environmental responsibility concept is not formed.

Secondly, enterprises' enterprise environment cost control system is not sound enough. At present, most enterprises in China adopt traditional environment cost control mode which takes end treatment as the major means. Enterprises still stay on treatment of "three kinds of wastes" (exhaust gas, waste water and waste residue) in terms of enterprise environment cost control. Environment cost control fails to overall pass through the whole process of product production. Enterprises often apply post treatment method. In this way, enterprises neither implement effective control of environmental harm sources in raw material purchase, production and consumption links, nor restrain adverse effects on the environment. Enterprises have been in the condition of passively making up for the loss. Thus, enterprise environment cost keeps high.

Thirdly, the specific standards of enterprise environment cost control are not sound enough. Nowadays, Chinese enterprises usually control the mixed environment cost and other cost. They seldom or do not formulate single environment cost control standards at all. Thus, enterprise environment cost is out of control. This will certainly bring about adverse influence on economic benefit and social benefit.

Fourthly, there is very shortage of professional talents of environment cost control. At present, some practical problems in talent training of financial accounting specialty in institutions of higher learning and employers' recruitment management cause that Chinese enterprises are faced with the situation of bad shortage of environment cost control talents. Enterprise environment cost control is a technique with distinct comprehensiveness and expertise, and it involves financial accounting, environmentology and economics etc, But, seeing from current actual conditions, even if Chinese enterprises have professional environment cost control personnel, they often have low knowledge 
level, poor practical operation ability and poor work experience. This greatly affects actual effect of environment cost control work.

\section{Measures to drive enterprise environment cost control under haze background}

\section{Establish environment cost control idea.}

Under haze background, it is required to drastically promote the new idea of environment cost control in enterprises so that employees can overall participate in environment cost control and realize enterprise environment cost control is closely related to the company. If necessary, environment cost control idea can be regarded as an important constituent part of enterprise culture and promoted in the enterprise. It is required to further implement enterprise environment cost control responsibility mechanism, and allocate specific environment cost control responsibility to each department or individuals so as to better find out the problems of enterprise environment cost control and carry out targeted improvement.

Improve laws and regulations about environment accounting.

Environmental resource is a kind of public resources. It is required to implement effective supervision and management. Thus, governmental agencies should formulate corresponding accounting laws and regulations according to actual conditions, let enterprises more explicitly cognize their social responsibility for environmental protection and sustainable development, make enterprises have rules to follow in environment cost accounting and guide enterprises to carry out environment cost control. On this basis, the government can apply policy means to actively encourage enterprises to implement clean production. For example, the government may implement certain tax preference for energy-saving and environmental protection industry so as to improve enterprises' enthusiasm for environment cost control. Of course, the government also should formulate and issue relevant system of rewards and penalties so as to accelerate local economic development, transformation and upgrade and achieve the goal of improving and optimizing industrial structure.

\section{Improve enterprise environment cost control system.}

With regard to specific control of enterprise environment cost, beforehand, in-process and post management control should be implemented. Firstly, beforehand control is to overall and fully assess possible environment cost expenditure of the product in the product design and development period, and list this in cost budgeting system. Then, cost-benefit analysis is used to implement all-round assessment and feasibility analysis for product design method so as to find out the most ideal design method, prevent and control environment cost in the resource. in-process control is to consider possible damage to the environment in each link such as material purchase, product production and selling so as to reduce environment cost. In raw material supply process, nonhazardous wind energy and solar energy with little pollution etc. should be used as far as possible. In product processing and manufacturing period, utilization efficiency of raw material and energy should be improved as far as possible. Before the enterprise produces wastes, the quantity and toxicity of wastes should be controlled maximally. In product selling and using period, environmentally-friendly and recyclable external packing materials should be chosen as far as possible, and strict design should be made to achieve minimization of packing. Thirdly, post-control is to eliminate and make up for environmental pollution accidents as far as possible. Once the environmental accident occurs, enterprises must try all means to actively take all remedy actions so as to practically eliminate environmental influence, compensate and even reverse the healthy, environmentally-friendly and green public image as well as protect good popularity and reputation of the products and enterprise in the whole market. Enterprises must look at the overall situation, closely combine beforehand control, in-process control and post-control and overall achieve ideal combination of economic benefit and environmental benefit according to internal and external environment of enterprises and the whole process of product life cycle. 


\section{Improve enterprise environment cost accounting mechanism.}

To promote enterprise environment cost control under haze background, it is required to further improve enterprise environment cost accounting mechanism which is very important for environment cost identification and control and can practically improve enterprises' cognition and analysis of environment cost. Therefore, it is required to drive enterprise environment cost control work and effectively reduce enterprise environment cost. Enterprises should formulate a more sound and perfect environment cost accounting mechanism so as to overall and accurately play its role in cost control. Meanwhile, it is required to effectively deploy and classify each production link of enterprises so as to provide more explicit and comprehensive cognition of enterprise production environment and lay a favorable institutional foundation for better implementing environment cost control.

\section{Train professional talents for high-quality environment cost control.}

Whether can enterprises' environmental responsibility cost be well controlled? An important factor is whether enterprises have environment accounting talents. Thus, enterprises must change their control idea and gradually transform the goal of economic benefit maximization to win-win of economy and environment under haze background. Moreover, enterprises should continuously intensify training professional quality of enterprise environment cost control talents and blend it into each relevant discipline. Of course, enterprises can more comprehensively master professional knowledge of environment cost control through regular or irregular topic training, guide employees to form the new concept of environment cost control and continuously boost the effect of enterprise environment cost control so as to effectively reduce corresponding expense of environment cost control.

\section{Conclusion}

In one word, under the background where it is very hard to completely control the haze, environment cost control work in China still has a long way. Although the difficulty in implementing enterprise environment cost control in the whole society is very tremendous, relevant departments can supervise and urge enterprises to enhance environment cost control. Besides, this is very important for promoting social harmony and stability and implementing the idea of sustainable development. Enterprises must improve their environment cost control mechanism so as to really achieve unification of social benefit and economic benefit.

\section{References}

[1] Zhang Hongqiu, Exploration on environment cost control internalization of export-oriented enterprises, Economic Research Guide, 2013 (6).

[2] Xu Hong, Yu Lifeng, Study on enterprise environment cost measurement, Research on Economics and Management, 2013 (8).

[3] Li Yonghai, Analysis on strategic control of enterprise environment cost under ecological economy background, Chinese Certified Public Accountant, 2013 (8).

[4] Sai Na, Tang Jinwei, Research on enterprise environment cost management based on low carbon economy, Economic Forum, 2014 (8).

[5] Zhu Xiaoming, Chen Nanyue, Definition of environment cost under low carbon economy - case study of thermal power enterprises, China Collective Economy, 2014 (6).

[6] Sun Chunli, Zhu Shengping, Discussion on enterprise environment cost control under low carbon economy, Cuide to Business, 2015 (5). 